\title{
PLANNING FOR ACCESSIBLE JOBS: THE CASE OF BANGALORE METROPOLITAN AREA, INDIA
}

\author{
GARGI GHOSH \\ Urban Planner, Sky Group, India
}

\begin{abstract}
This paper investigates the spatial job accessibility in the Bangalore Metropolitan Area through an accessibility measurement technique. Methods of measuring accessibility have been studied from available literature and a location-based cumulative accessibility measure has been chosen to interpret job accessibility at aggregate level. The method is found most suitable for the purpose of ascertaining accessibility in the catchment area of transit stations. The statutory master plan of Bangalore, the public transport network - namely, the bus network, metro network and suburban railway are the prime data sources. Spatial data in vector form has been analysed on an integrated GIS platform. The preliminary result of the study shows the accessibility pattern of the jobs in the city through public transport. Consequently, a secondary study has been done to assess the potential high accessibility locations of jobs in the city using data of population density, land use and transit stations. The results have been presented in the form of choropleth map outputs showing the high and low potential areas.
\end{abstract}

Keywords: jobs, employment, accessibility, Bangalore, spatial planning, master plan, transit, station.

\section{INTRODUCTION}

Access to economic opportunities and its relation to social inclusion and economic upliftment is an area of work that has been explored extensively in the field of urban planning, transportation and sociology. One of the first works to establish the relation between accessibility and social inclusion is that of Sen [1] based on the Great Bengal Famine of 1943. His work conclusively established social exclusion is not a function of unavailability of the service or the opportunity but rather a lack of access to it. It was possibly in 1968, that in the conference and related papers in the American Association for Art and Science, the relationship between inadequate transportation and poverty was hinted. Thereafter there has been ample work in the segment of urban transportation links, labour markets and economic opportunities. It is therefore also important that spatial organisation of our cities promotes accessibility to key social services like jobs, healthcare and education.

The current paper works on similar premises of land use, transportation system and job accessibility. The focus of the paper is to understand the job accessibility in integrated GIS system and thereafter establish an ideal spatial organisation of jobs and employment in the study area. The first section of the paper establishes the objectives of the research, its scope and limits. Relevant literature in this area of work is reviewed in the next section. The subsequent section establishes the methodology of the work. The summary of the observed trends in Bangalore in job accessibility have been depicted, and thereafter the ideal spatial organisation of jobs has been deliberated upon. The last section is a brief conclusion.

\section{OBJECTIVES AND SCOPE OF STUDY}

The concept of accessibility has been explored in the field of urban planning and transportation planning in a multitude of ways for determining the utility of services and infrastructure. Accessibility in the present paper looks at job accessibility at an aggregate level as an interaction between land use and transportation in the case study area of Bangalore Metropolitan Area. It has been established that the jobs in Bangalore are fairly accessible by metro service [2]. In the present study bus network, proposed metro networks and sub-urban 
railway network has also been added to the gamut of public transport. Hence the preliminary discussion area of the paper is to review the accessibility of the jobs with respect to the new framework of public transport i.e. bus, metro along with sub-urban railway. The succeeding discussion area is to deliberate upon the desirable spatial distribution of jobs areas in the city.

\section{LITERATURE REVIEW}

\subsection{Review of models of accessibility}

The definitions and measures of accessibility in transportation engineering, transportation planning urban planning and sociology are plentiful. Accessibility has been broadly been described as ease with which a particular service could be availed. The definition has been transformed as per the requirement and premise of the respective research. In works of Geurs and Wee [3], the measures have been classified into three main categories namely infrastructure-based, location-based and utility-based. Ben-Akiva and Lerman [4] identified three types of accessibility measure namely isochrones measures or cumulative measures, gravity-based measures and utility-based measures. A simple review of the measurement techniques has been presented in this section.

Isochrone measures or cumulative opportunity-based measures have been depicted in work by Wachs and Kumagai [5] and Vickerman [6]. It is primarily a count of the number of opportunities that can be reached within a given travel time or distance or cost. The advantage of this measure is its ease of interpretability, though it is highly sensitive to the range specified. It is a favoured mode of measurement in urban planning as it is useful in measuring accessibility at aggregate level where components of individual factors are unimportant.

Infrastructure-based accessibility measures work primarily in the premises of interpreting the performance of transportation systems based on factors like travel times, congestion and operating speed. Such measures have been known to be used in the Dutch National Transport Policy Plan as well as the UK Transport 2010 policy plan. This measure is effective in accessing a transport system but does not incorporate factors of land use, temporal or individual components.

The gravity model is also one of the quintessential accessibility measurement models. It is defined as the ease of reaching a certain opportunity with a factor if impedance. The cost of moving between the origin and destination determines the attractiveness of an opportunity. The further the distance of the destination the lesser is the attractiveness. The choice of impedance factors has a big impact in determining the attractiveness of an opportunity.

A utility-based measure is one of the most accurate as well as data intensive and complicated ways to measure accessibility [3]. The measure has been elaborated in the works of Ben-Akiva and Lerman [7] - the measure of travel behaviour theory based on macro-economic theory of user behaviour. It says that a choice made by a person for one trip over another is directly dependent the utility drawn by the person for making that choice over another. The theory is consistent with the traditional microeconomic theory of consumer surplus that accessibility represents the benefits provided by transportation choices.

The models can be largely categorised into two categories, namely, land-use-based models and econometric models. In the study of the various measures, four components gave been identified as most crucial namely land use, transportation, temporal and individual. The land-use component reflects the availability of supplies at destination and the demand for the same at the origin location. The transportation component reflects the disutility of travel including time spent parking, waiting, costs and effort. The temporal components reflect the 
time-based constraints like availability of service at different times of the day. The individual component represents variables such as need, ability and opportunity of the individuals.

The University of Minnesota in its Accessibility Observatory project 2017 [8] has analysed the job accessibility of 49 metros in USA. The project utilises the cumulative accessibility measurement technique to measure the simple count of destinations from each census block for accessibility evaluation.

This paper focuses on the accessibility of the jobs through public transit based on the existing and future public transport network. It essentially measures accessibility as a function of number of opportunities that can be reached within a particular distance from the transit stations. Individual variables such as distance between origin and destination, number of interchanges, cost, comfort and temporal factors are not part of the study. The premise of this paper deals with the factors influencing the interface of land use and the transit station. Hence, the cumulative accessibility measurement technique or the isochrone model has been adopted for determining the jobs availability for the purpose of this study.

\subsection{Review of literature on walkability around transit stations}

It has been established in plethora of works that pedestrian link between the transit station and the immediate surroundings are a key to success of public transportation and land-use strategies based on public transportation. This section of the paper investigates the feasible walking distances between the transit station and the surrounding. In works by Howe et al. [9], Cascetta and Pagliara [10], Cervero and Murakami [11] and Loo et al. [12], the various scales of transit-oriented development (TOD) has been discussed. It has been well documented in the papers that accessibility from regional transit stations should ideally be a mix of walk, paratransit and non-motorised modes while access from urban or city level should consider walking modes only. While access from station areas essentially consists of indicators like safety, urban design, pedestrian pathway quality parking among others for the present paper the only the distance factor has been considered in measuring accessibility. In order to make the transport and urban systems more efficient, the Ministry of Urban Development, Govt. of India has published a transit-oriented development policy to set benchmarks for the TOD in Indian cities. The TOD policy sets the walkable distance at $500 \mathrm{~m}$ from the mass rapid transport systems (MRTS) and bus rapid transport system (BRTS). For the purpose of this study, the walkable distance around the bus stops and metro rail stations which cater primarily to the city traffic, has been considered to be $500 \mathrm{~m}$ and that around sub-urban railway stations, which cater to regional traffic has been considered to be $800 \mathrm{~m}$.

\section{METHODOLOGY}

\subsection{Overview}

The Bangalore Metropolitan Area (BMA) is the study area for the present case. The bus transport, metro rail and suburban railway have been considered as public transport system of the city. The statutory land-use plan of the city called the master plan denotes the land uses in various areas. The plan has been used for understanding the job and employment potential of the station areas. The vector datasets of land use and transport network has been analysed in integrated GIS environment. The accessibility to jobs around station areas has been computed by spatial computation techniques in GIS. Jobs availability has been considered as a function of job generating land use such as commercial and industrial land uses. The study 
area has been divided into $0.5 \mathrm{~km}$ by $0.5 \mathrm{~km}$ spatial grids in GIS platform on which the land use and the transportation datasets have been analysed. Grids containing transit stations are the ones with high transport accessibility while the grids containing higher percentage of commercial or industrial land use are the grids with high job density. Analytical operators in GIS have been used thereafter to arrive at the results.

\subsection{Study area and job availability}

The Bangalore Metropolitan Area (BMA) is primarily the planning jurisdiction of the Bangalore city and is about $1307 \mathrm{sqkm}$ in extent. Though most of the areas under BMA is urbanised, parts of the area are as rural and categorised "village" as per the administrative classification. The municipal jurisdiction is shared by the Bruhat Bangalore Mahanagara Palike (BBMP) which is a municipal corporation and takes care of the municipal functions of the urban area along with several Gram Panchayats which take care of the villages. The total population of the BMA is about 9 million.

The spatial plan or the land-use plan of BMA has been prepared by the Bangalore Development Authority in 2007 called the Revised Master Plan. The master plan consists of land use plan of BMA denoting various use types such as residential, commercial, industrial, park and open spaces, water bodies and transportation areas. The master plan identifies a conurbation limit within the BDA measuring about $871 \mathrm{sqkm}$, which is essentially the urbanisable area. The area beyond the urbanisable limit till the periphery of the BMA is a green belt consisting of agricultural land and small village settlements. Approximately $117 \mathrm{sqkm}$ of the urbanised area has been zoned under commercial and industrial use. The enumeration of jobs for the purpose of the present paper has been made using a "jobs/unit area" conversion of the area under industrial and commercial land use. The unit of conversion has been adopted as 110 jobs per acre based on secondary sector job generation standard in India. Fig. 1 shows the master plan of Bangalore.

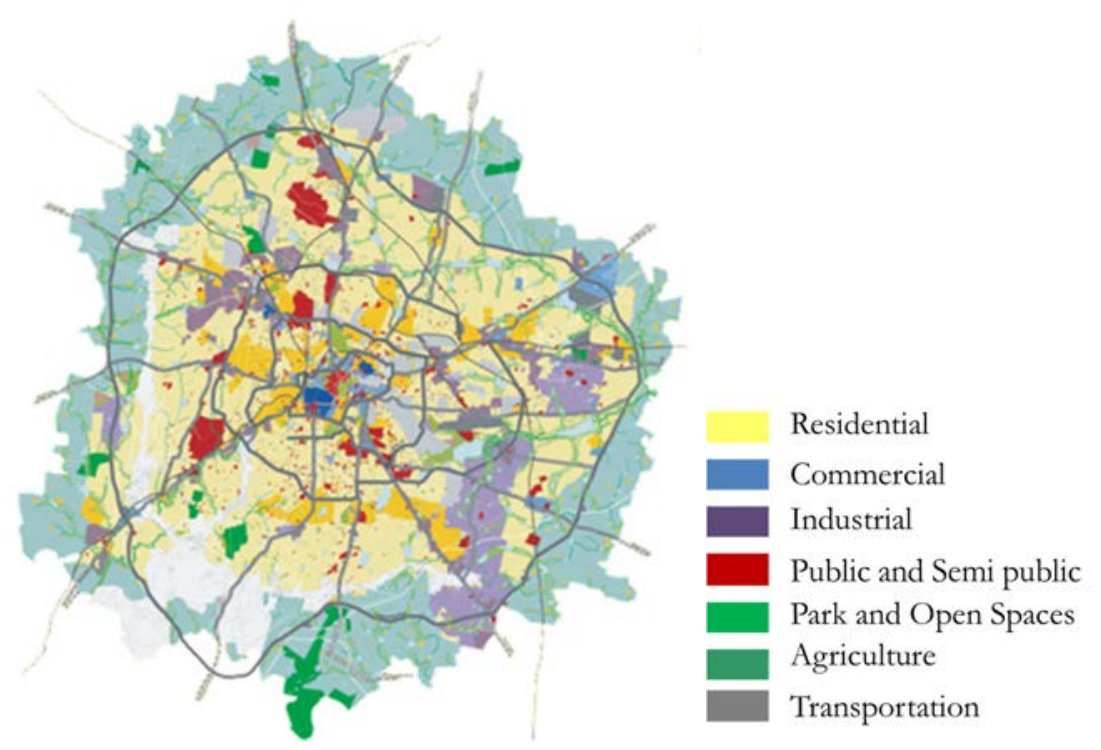

Figure 1: Proposed land-use map of the BMA. (Source: BDA, 2007 [13].) 


\subsection{Public transport network}

The public transportation system in BMA consists of bus transport run by the Bangalore Metropolitan Transport Corporation (BMTC), the metro rail run by the Bangalore Metro Rail Corporation Ltd (BMRCL) and the sub urban railway operated by the Indian Railways. The coverage of the bus transport system is extensive, and buses are operated on both arterial and sub arterial roads. The metro rail operates only on the key traffic corridors and is elevated and underground in parts. It provides high speed connectivity between different zones of the city. The map of Bangalore showing the bus stops and metro rail network is shown in Fig. 2.

The suburban railway system is a part of the regional rail network of Bangalore which has been proposed as a modern high-speed rail network that connects Bangalore city to the greater Bangalore region through at ground and elevated tracts. The network and stations of the railway has been shown in Fig. 3.
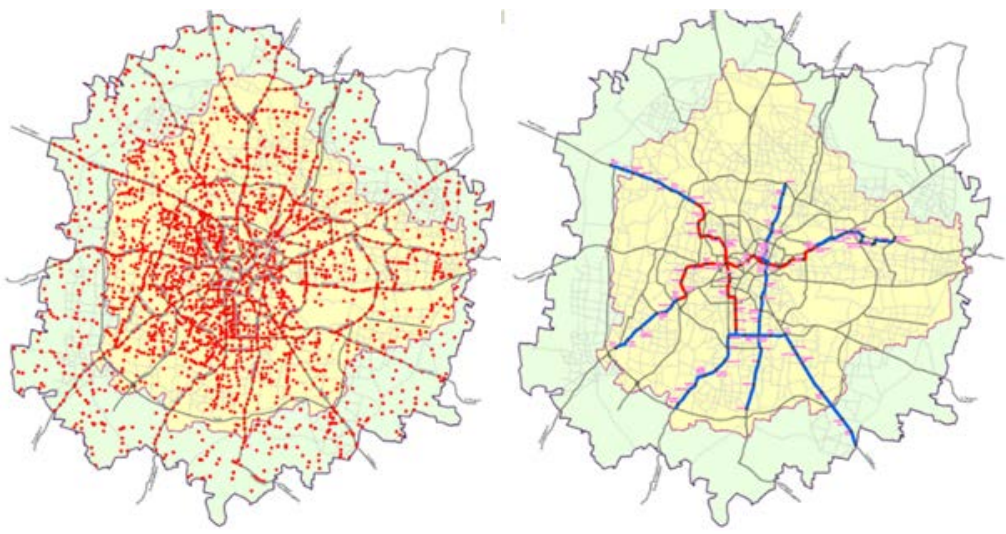

Figure 2: Bus stop and metro network map of Bangalore.

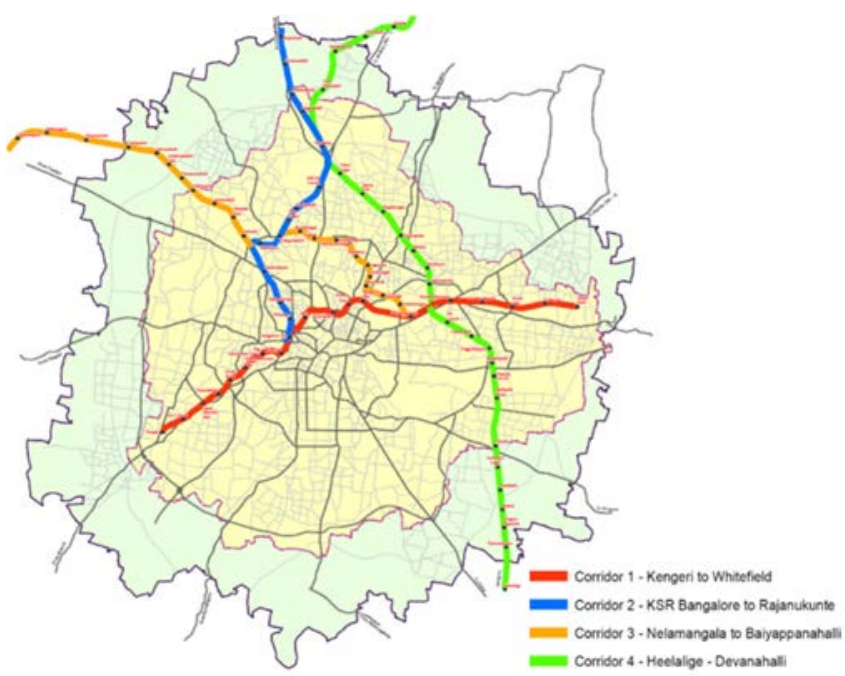

Figure 3: Suburban railway network in Bangalore. 


\section{EXISTING SCENARIO OF JOB ACCESSIBILITY}

The assessment of job accessibility has been done in an integrated GIS environment using vector data sets of land use and the transportation using analytical operators using the methodology explained previously. The existing job density in Bangalore is interpreted as a function of percentage of commercial and industrial land use per grid. The outputs of the analysis have been presented in the form of job density gradient map. Fig. 4 shows the overall job availability in BMA. It seems there are broad concentrations of employment areas in the city core and south-east arc, the north west arc and south-west road corridor. It signifies that jobs in Bangalore have been decentralised through active planning measures.

The subsequent step of the study was to evaluate the extent of accessibility of the jobs from transit stations. Fig. 5 presents the job density gradient for availability of jobs within accessible distance around the bus stops, metro stations and suburban railway stations. It can be seen that the accessibility of the jobs is highest by bus transport followed by metro rail and then by suburban railway.

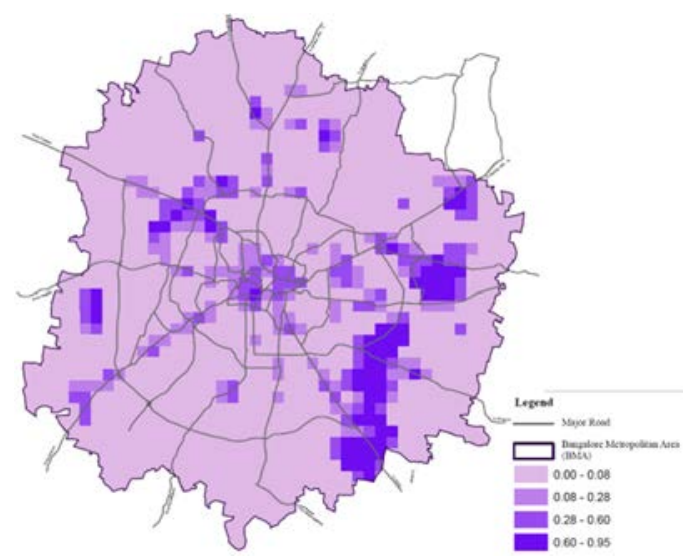

Figure 4: Density gradient of job distribution in BMA.

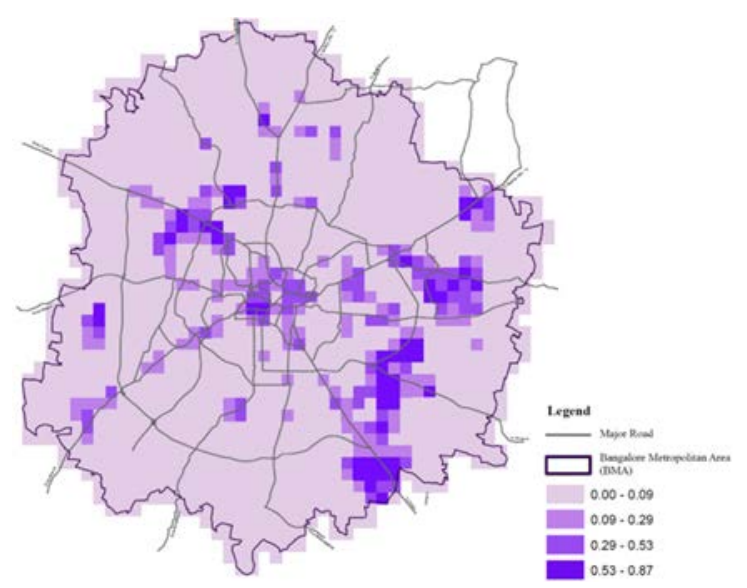

Figure 5: Density gradient of job availability by public transport. 
It can also be observed that a significant number of jobs appear to be inaccessible through public transport. The jobs along the south-eastern arc appear to be least accessible by public transport. The accessibility of the jobs in the city centre as well as the south western road corridor also seem to be reduced.

\section{POTENTIAL AREAS OF JOB DISTRIBUTION FOR PUBLIC TRANSPORT ACCESSBILITY}

The proposal for a more favourable job distribution scenario has been done by considering the datasets of population density, transport network and land use. It has been assumed that the areas with existing high population density would require significant transformation of urban fabric for accommodating more jobs. Areas with low existing population density would be able to accommodate change of land use without significant disruption of the existing urban structure. The assumption is relevant for the urban fabric of Bangalore as the dense residential areas tend to have smaller property or plot sizes which cannot accommodate commercial development without amalgamation of properties.

Fig. 6 shows the existing population density in BMA. It can be seen that the central areas of the city are more dense, and the density decreases as we move outward from the centre.

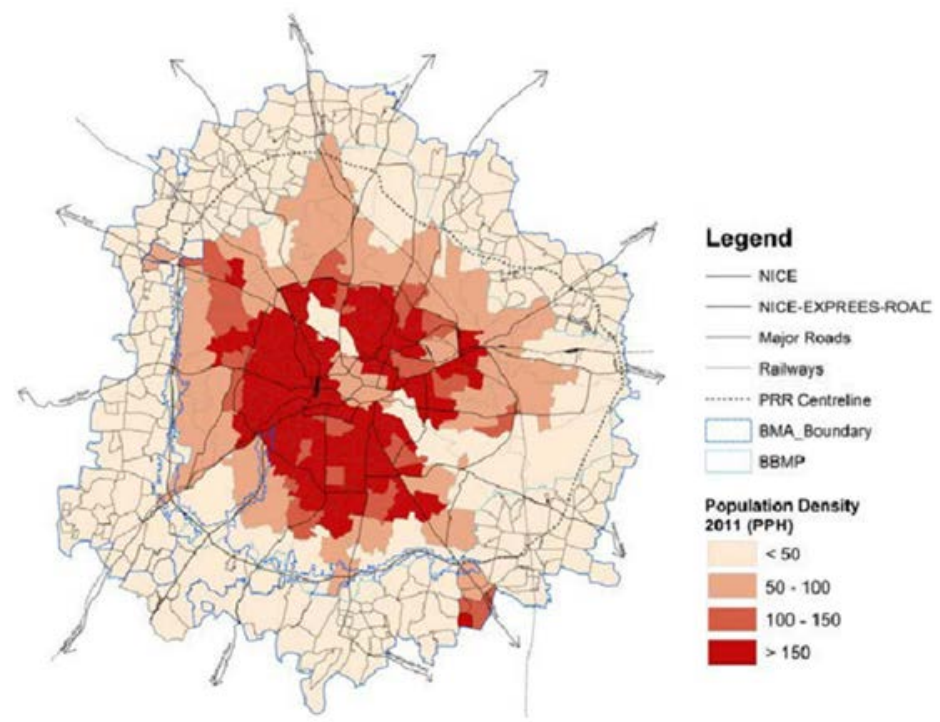

Figure 6: Population density of Bangalore. (Source: BDA, 2017 [14].)

A spatial analysis has been run in GIS environment with job density, station location and population density datasets to arrive at high potential areas for future job location. Grids containing transit stations have been considered as grids with high transport accessibility while grids with low population density have been considered as grids with higher potential of job densification. High potential grids have been generated by a superimposition of high transport accessibility grids and low population density grids on the existing low job density grids. The output has been presented in Fig. 7. The analysis identifies a new northeast arc, corridor extension in the south west Kanakapura road and an extension of the North West arc as the most suitable locations for employment for a favourable job access scenario. 


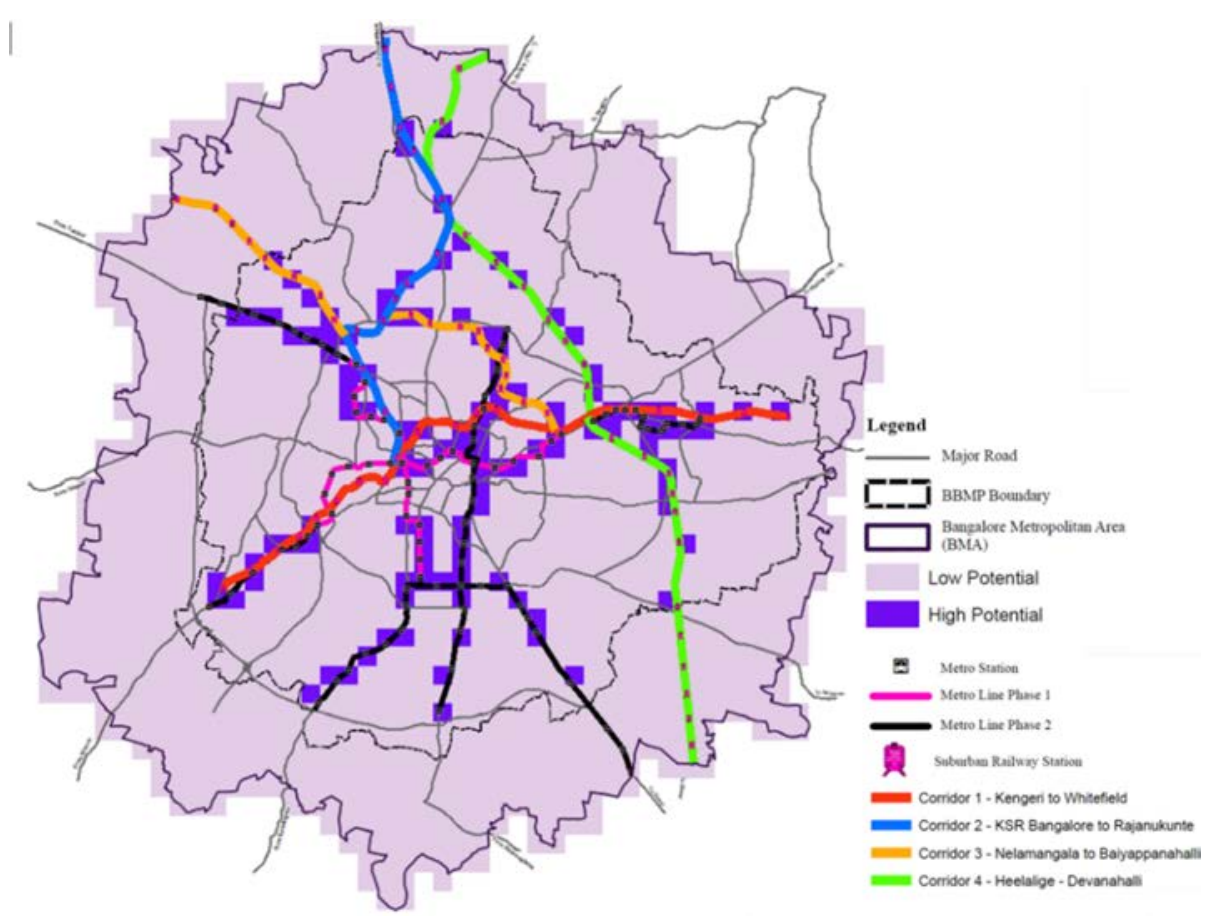

Figure 7: Potential locations for future job location.

\section{CONCLUSION}

The study on job accessibility in Bangalore has been based on cumulative accessibility measurement technique. It attempts to reveal that the job accessibility in Bangalore at the interface of the transit station and land use. The study brings out several interesting observations related to land use, transportation and jobs in Bangalore. It can be seen that the jobs in Bangalore are not concentrated at the city centre; they have been decentralised though active planning measures. The job density map displays that the major job areas are the city centre, the south-eastern arc, the north-western arc and the south-west road corridor. The public transportation network has also been discussed in detail. The network is well established and covers all urbanised areas. The bus and the metro rail cover the city limits while the suburban railway caters to regional mobility. The coverage of the bus transport is the highest followed by metro rail and suburban railway.

Accessibility has been computed using spatial computation techniques in GIS using datasets of land use and transit station locations. The study of accessibility establishes that the accessibility of the jobs is highest by bus transport followed by metro rail and then by sub urban railway. It can be also interestingly observed that the relation between jobs and sub urban rail network appear to be the least even though the suburban railway is effectively positioned to carry majority of the regional commuters. It was established that the accessibility of jobs by public transport is significantly reduced in the south-eastern arc and to some extent in the city centre and well as the south west road corridor.

The investigation of potential areas for locating job generating land use such as commercial and industrial land use was carried out using spatial datasets of land use, transit stations and population density. While evaluating it was found that the areas along the north 
eastern and north western are ideal or planning for future job areas. The major road corridors also emerged as the potential areas. These areas also coincide with the alignment of the metro rail and suburban railway. It indicates that the potential of the metro rail and the suburban railway can be explored to provide accessible jobs in Bangalore. The study demonstrates the use of a simple methodology to measure accessibility using aggregate spatial data in GIS platform. The methodology has been previously used with statistical data sets in several cities in the USA with significant success, the details of which were outlined in the initial sections of this paper. The present technique can be used as a practical approach for preparation of land-use plans as a quantitative basis of locating land use.

\section{ACKNOWLEDGEMENTS}

This paper is based on on-going works in our organisation and I would like to thank my colleagues who have taken time out of their busy schedule to support by work. I would like to acknowledge with gratitude the love and support of my family. I thank my husband and peer, Akash who has been instrumental in encouraging me to finish this paper; my parents Tapati and Bimalendu to whom I am forever in debt for the discipline and education they inculcated in me since childhood; my wonderful brother Rahul who has a 'pick-me-up' any time of the day; my parents in law, Hamsa and Mahesh who have supported by every endeavour with a lovely smile and last but not the least, my son Samak who is happiness personified and the source of smiles in my life.

\section{REFERENCES}

[1] Sen, A., Poverty and Famines: An Essay on Entitlement and Deprivation, Clarendon Press: Oxford, 1981.

[2] Ghosh, G., Landuse planning for social accessibility: A case of Bangalore, India. WIT Transactions on The Built Environment, vol. 182, WIT Press: Southampton and Boston, 2019.

[3] Geurs, K.T. \& Wee, B.V., Accessibility evaluation of land-use and transport strategies: review and research directions. Journal of Transport Geography, 12(2), pp. 127-140, 2004.

[4] Ben-Akiva, M. \& Lerman, S.R., Disaggregate travel and mobility choice models and measures of accessibility. Presented at Third International Conference on Behavioral Travel Modeling, Tanenda, Australia, 1977.

[5] Wachs, M. \& Kumagai, T.G., Physical accessibility as a social indicator. Socioeconomic Planning Science, 7, pp. 327-456, 1973.

[6] Vickerman, R.W., Accessibility, attraction and potential: A review of some concepts and their use in determining mobility. Environment and Planning A, 6, pp. 675-691, 1974.

[7] Ben-Akiva, M. \& Lerman, S.R., Disaggregate travel and mobility choice models and measures of accessibility. Presented at Third International Conference on Behavioral Travel Modeling, Tanenda, Australia, 1977.

[8] Owen, A., Murphy, B. \& Levinson, D., Access Across America: Transit 2017 Methodology, CTS 18-13, Center for Transportation Studies: Minnesota, 2018.

[9] Howe, A., Glass, G. \& Curtis, C., Retrofitting TOD and managing the impacts: The case of Subi Centro. Transit Oriented Development: Making it Happen, eds C. Curtis, J.L. Renne \& L. Bertolini, Ashgate eBook, pp. 65-74, 2009.

[10] Cascetta, E. \& Pagliara, F., Rail friendly transport and land-use policies: The case of the regional metro system of Naples and Campania. Transit Oriented Development: 
Making it Happen, eds C. Curtis, J.L. Renne \& L. Bertolini, Ashgate eBook, pp. 4964, 2009.

[11] Cervero, R. \& Murakami, J., Rail and property development in Hong Kong: Experiences and extensions. Urban Studies, 46, pp. 2019-2043, 2009.

[12] Loo, B.P.Y., Chen, C. \& Chan, E.T.H., Rail-based transit-oriented development: Lessons from New York City and Hong Kong. Landscape Urban Plan, 97, pp. 202212, 2010.

[13] Bangalore Development Authority (BDA), Revised master plan for Bengaluru - 2015, 2007.

[14] Bangalore Development Authority (BDA), Revised master plan for Bengaluru - 2031 (draft), vol. 3, 2017. 